\title{
COMMUNITY EMPOWERMENT IN LANDSLIDE DISASTER MITIGATION THROUGH GREEN REVITALIZATION SYSTEM TO REALIZE TANGGUH DISASTER COMMUNITY
}

\section{PEMBERDAYAAN MASYARAKAT DALAM MITIGASI BENCANA LONGSOR NAGARI SALIDO MELALUI SISTEM REVITALISASI HIJAU GUNA MEWUJUDKAN MASYARAKAT NAGARI TANGGUH BENCANA}

\author{
ling Rika Yanti ${ }^{1^{*}}$, Silvi Trisna ${ }^{2}$, Rahmi Zulva ${ }^{3}$, Helendra $^{4}$ \\ ${ }_{1,2,3,4}$ STKIP PGRI Sumatera Barat \\ E-mail: iing1408@gmail.com
}

\begin{abstract}
Natural disasters are inevitable and predictable. Over the past few years there have been numerous landslides in some disaster-prone areas. Landslides caused by unstable soil conditions as well as a lack of public awareness will keep themselves from landslide hazards. One of the areas prone to landslides is nagari salido kecematan IV Jurai South Coast which will receive the impact of landslide disaster. One of the efforts that can be made is to provide knowledge of landslide disaster mitigation through green revitalization to realize the community of disaster-resilient nagari. So that the community will have the readiness to face the disaster and the ability to reduce the risk, as well as have the resilience and strength to rebuild lives after being affected. In addition to counseling, green revitalization is carried out through the replanting of forests that have been bald with plant seeds that are expected to increase soil aggregates so that landslides do not occur again. The entire series of activities at this stage is also referred to as an early model in the reduction of the risk of landslide disasters.
\end{abstract}

Keywords: Landslide, Green Revitalization, Disaster Resilient Nagari

\begin{abstract}
ABSTRAK
Bencana alam merupakan suatu yang tidak dapat dihindari dan diprediksi terjadinya. Selama kurun waktu beberapa tahun belakangan ini banyak terjadi bencana longsor di beberapa daerah yang rawan bencana. Longsor yang terjadi disebabkan karena kondisi tanah yang tidak stabil serta kurangnya kesadaran masyarakat akan menjaga lingkunagn sendiri dari bahaya longsor. Salah satu daerah yang rawan longsor adalah nagari salido kecematan IV Jurai Pesisir Selatan yang akan menerima dampak bencana longsor. Salah satu upaya yang dapat dilakukan adalah dengan memberikan pengetahuan mitigasi bencana longsor melalui revitalisasi hijau guna mewujudkan masyarakat nagari tangguh bencana. Sehingga masyarakat akan memiliki kesiapan untuk menghadapi becana dan kemampuan untuk mengurangi resiko, serta memiliki ketahanan dan kekuatan membangun kembali kehidupan setelah terkena dampak. Selain penyuluhan juga dilakukan revitalisasi hijau melalui penanaman kembali hutan yang telah gundul dengan bibit-bibit tanaman yang diharapkan dapat meningkatkan agregat tanah sehingga longsoran tanah tidak terjadi lagi. Seluruh rangkaian kegiatan pada tahap ini disebut juga sebagai model awal dalam pengurangan risiko bencana tanah longsor.
\end{abstract}

Kata kunci: Longsor, Revitalisasi Hijau,Nagari Tangguh Bencana 


\section{Rangkiang: Lurnal Pengabdian Pada Masyarakat \\ UPSM STKIP PGR/ Sumatera Barat}

ISSN: (2721-2688) Vol. 2 No 2 (Desember 2020): 118-123

\section{PENDAHULUAN}

Pendahuluan mencakup latar belakang atas suatu permasalahan serta urgensi penelitian, tujuan penelitian dan rencana pemecahan masalah, tinjauan pustaka yang relevan dan atau pengembangan hipotesis. Hal yang dapat ditulis dalam pendahuluan:

Kata pemberdayaan sudah sering kali terdengar ketika ada suatu masalah di dalam sebuah masyarakat. Dan Pemberdayaan itu adalah keadaan-keadaan yang terjadi atau halhal yang dilakukan di lingkungan masyarakat dengan upaya membangun pembangunan yang bertumpu pada masyarakat itu sendiri. Masyarakat yang berada di desa/kelurahan adalah penerima dampak langsung dari bencana, dan sekaligus sebagai pelaku yang akan merespon bencana di sekitarnya. Dan ancaman bencana adalah suatu kejadian atau peristiwa yang dapat menimbulkan bencana. Oleh karena itu, dengan memanfaatkan semua potensi sumberdaya yang dimiliki, masyarakat desa/kelurahan dapat menjadi tangguh terhadap dampak bencana, sehingga risiko korban jiwa, kerugian harta, dan lain-lain akan bias diperkecil dan bahkan dihindari.

Kata bencana sendiri menurut UU No. 24/2007 adalah "Peristiwa atau rangkaian peristiwa yang mengancam dan mengganggu kehidupan dan penghidupan masyarakat yang disebabkan, baik faktor alam, non alam maupun manusia, sehingga menyebabkan timbulnya korban jiwa, kerusakan lingkungan, kerugian harta benda dan dampak psikologis". Bencana alam merupakan suatu proses yang dinamis, dan tidak dapat dihindari dan diprediksi terjadinya. Selama kurun waktu beberapa tahun belakangan ini banyak terjadi bencana alam. Berdasarkan pengertian di atas maka dapat disimpulkan bahwasanya peristiwa bencana ini dapat menimbulkan kerugian yang besar dan dapat mengganggu kelangsungan hidup masyarakat. Salah satu peristiwa bencana alam yang sering terjadi adalah tanah longsor.

Longsor adalah keadaan dimana tanah atau daratan yang bergerak akibat kondisinya yang tidak stabil. Sehingga memungkinkan warga sekitar untuk mengamankan barangbarangnya dan beralih ke posko pengungsian terdekat. Longsor yang merugikan ini bukanlah datang tanpa sebab, tak lain adalah karena ulah manusia itu sendiri. Seperti kelalaian manusia dalam membangun tempat tinggal tanpa memerhatikan saluran air, buang sampah sembarangan, dan minimnya perhatian masyarakat terhadap lingkungan sekitar. Sehingga banyak hal yang diakibatkan oleh longsor yang merugikan manusia itu sendiri. Banyak dari masyarakat yang terkena dampak akibat longsor seperti kerusakan bangunan bahkan kehilangan tempat tinggal. Serta lalu lintas bisa macet total jika longsornya mengenai jalan raya. Perlu diperhatikan bahwa setiap lapisan masyarakat guna untuk memberi bekal kepada setiap masyarakatnya agar selalu siap siaga bencana dan memberdayakan kelompok masyarakat tanggap bencana.

Bencana tanah longsor menjadi masalah yang serius di beberapa daerah di Indonesia, karena kejadiannya selalu meningkat dari tahun ke tahun. Pesisir Selatan merupakan salah satu kabupaten di Sumatera Barat yang masuk kedalam daerah yang memiliki tingkat kejadian gerakan tanah cukup tinggi diantara kabupaten/kota lainnya. Daerah-daerah yang termasuk rawan tanah longsor di Provinsi Sumatera Barat diantaranya Nagari Salido Pesisir Selatan. Fakta-fakta tersebut memperlihatkan masih lemahnya kesiapsiagaan menghadapi bencana di Indonesia. Kesiapsiagaan merupakan langkah strategis dan sangat penting mengingat fakta bahwa jumlah kejadian dan korban jiwa akibat bencana khususnya tanah longsor setiap tahunnya meningkat (Rinaldi dalam Sudaryono,(2013:2). Sehingga diperlukan suatu kegiatan pencegahan agar peristiwa ini tidak terjadi atau setidaknya meminimalisir dampak atau resiko dari peristiwa ini. 


\section{Rangkiang: Lurnal Pengabdian Pada Masyarakat UPSM STKIP PGR/ Sumatera Barat}

ISSN: (2721-2688) Vol. 2 No 2 (Desember 2020): 118-123

Oleh karena itu, Program Studi Pendidikan Fisika STKIP PGRI Sumatera Barat melakukan suatu program terhadap masyarakat dalam menghadapi suatu bencana alam dengan melaksanakan program desa tangguh bencana di kenagarian Salido yang terdampak bencana longsor. Masyarakat yang berada di kenagarian Salido adalah penerima dampak langsung dari bencana, dan sekaligus sebagai pelaku yang akan merespon langsung bencana di sekitarnya. Dengan memanfaatkan semua potensi sumberdaya yang dimiliki, masyarakat dikenagarian Salido dapat menjadi tangguh terhadap dampak bencana, sehingga risiko korban jiwa, kerugian harta, dan lain-lain akan bisa diperkecil dan bahkan dihindari. Oleh karena itu mitigasi bencana perlu diberdayakan kepada untuk menghadapi peristiwa tersebut.

Dalam UU no. 24 tahun 2007, Mitigasi Bencana adalah serangkaian upaya untuk mengurangi resiko bencana, baik melalui pembangunan fisik maupun penyadaran dan peningkatan kemampuan menghadapi ancaman bencana. Tujuan utama mitigasi bencana adalah (1) Mengurangi risiko bencana bagi penduduk dalam bentuk korban jiwa, kerugian ekonomi, dan kerusakan sumber saya alam; (2) Menjadi landasan perencanaan bangunan; (3) Meningkatkan kepedulian masyarakat. Bentuk mitigasi bencana yang telah dilakukan Program Studi Pendidikan Fisika adalah memberikan penyuluhan dengan meningkatkan kesadaran masyarakat akan dampak dari bencana longsor sehingga masyarakat lebih menjaga dan merawat kelestarian lingkungan. Selanjutnya melakukan revitalisasi hijau melalui penanaman kembali hutan yang telah gundul dengan bibit-bibit tanaman yang diharapkan dapat meningkatkan agregat tanah sehingga longsoran tanah tidak terjadi lagi. Seluruh rangkaian kegiatan pada tahap ini disebut juga sebagai model awal dalam pengurangan risiko bencana tanah longsor.

Rumusan masalah dalam pengabdian ini adalah bagaimana masyarakat sadar akan potensi bencana longsor di daerahnya, memiliki kesiapan untuk menghadapi bencana dan kemampuan untuk mengurangi resiko, serta memiliki ketahanan dan kekuatan untuk membangun kembali kehidupannya setelah terkena dampak bencana dan telah siap mengandalikan diri sendiri dalam upaya penanggulangan bencana yang akan datang.

Adapun tujuan dari kegiatan pengabdian ini adalah sebagai berikut :

1. Untuk penambahan pemahaman masyarakat tentang dampak dari bencana alam, khususnya bencana longsor.

2. Untuk menambah kesiapsiagaan masyarakat tentang kebencanaan serta menambah kesiapan masyarakat akan resiko bencana melalui kegiatan mitigasi bencana.

\section{METODE}

Metode yang digunakan dalam pelaksanaan kegiatan tersebut adalah dengan memberikan penyuluhan kepada masyarakat setempat mengenai kesadaran akan lingkungan, upaya pelestarian lingkungan, bahaya akan kerusakan alam serta upaya pencegahannya. Selanjutnya dilakukan penanaman kembali hutan yang telah rusak. Dengan adanya kegiatan ini diharapkan dapat meningkatkan kesadaran masyarakat akan pentingnya lingkungan untuk mencegah terjadinya bencana alam yang dapat merusak dan merugikan masyarakat itu sendiri. Adapun kegiatan yang dilakukan adalah sebagai berikut : 
Tabel 1. Tahap Kegiatan Pengabdian

\section{Minggu Pertama}

\begin{tabular}{lll}
\hline \multicolumn{2}{c}{ Kegiatan Tim Pengabdian } & \multicolumn{2}{c}{ Kegiatan Peserta Masyarakat Nagari } \\
Salido
\end{tabular}

\section{HASIL DAN PEMBAHASAN}

Pelatihan yang dilakukan di kenagarian salido kecematan IV Jurai Pesisir Selatan berupa penyuluhan dan penanaman hutan akan membuat masyarakat sadar akan bencana. Penanaman pohon diharapkan akan menahan air tanah pada hutan yang juga menjadi penyimpanan cadangan air manusia. Untuk penanaman pohon, memilih jenis pohon yang dapat menyerap air dengan optimal serta memberikan hasil dikemudian hari pada masyarakat sekitar seperti pohon jati, pohon durian, pohon jambu, pohon Nangka dan lain-lain. 


\section{Rangkiang: لurnal Pengabdian Pada Masyarakat UPSM STKIP PGR/ Sumatera Barat \\ ISSN: (2721-2688) Vol. 2 No 2 (Desember 2020): 118-123}

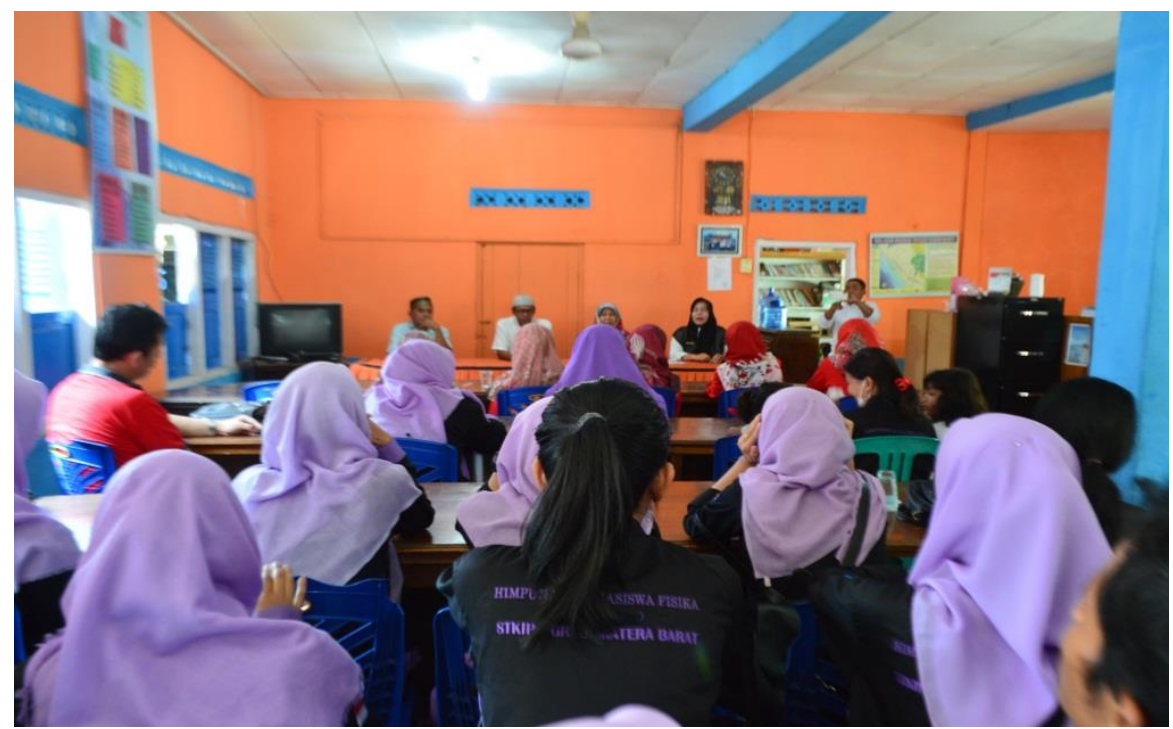

Gambar 1. Pemberian penyuluhan kepada masyarakat d kantor Wali Nagari Salido

Pemberian penyuluhan system revitalisasi hijau hutan ini mendapatkan manfaat yang luar biasa bagi masyarakat sekitar pesisir pantai. Masyarakat menjadi lebih mengetahui bagaimana cara mengelola hutan dengan baik sehingga dapat memanfaatkan hasil hutan dengan maksimal tampa meninggalkan efek bencana pada lingkungan masyarakat. Sehingga dapat mewujudkan program pemerintah untuk masyarakat yang tanggap bencana.

Selain itu dengan dilaksanakannya program pemberdayaan masyarakat dalam mitigasi bencana longsor melalui system revitalisasi hujau guna mewujudkan masyarakat nigari Tangguh bencana ini maka kawasan sekitar menjadi lebih aman dan stabil dalam menghadapi kemungkinan bencana alam yang dating. Dengan diberikannya penyuluhan tentang pemberdayaan hutan yang rawan longsor maka hutan pada daerah rawan bencana dapat dipelihara dengan baik.

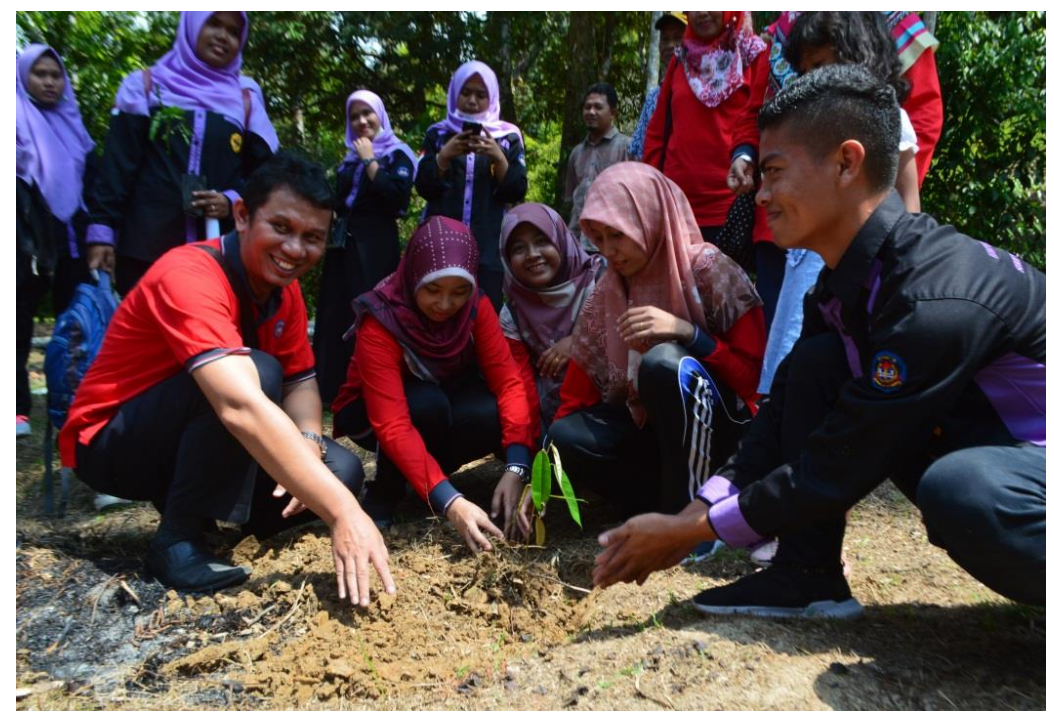

Gambar 2. Penanaman Pohon Di Daerah Rawan Longsor 


\section{SIMPULAN}

Pemberian penyuluhan system revitalisasi hijau hutan ini mendapatkan manfaat yang luar biasa bagi masyarakat sekitar pesisir pantai. Menambah pemahaman masyarakat tentang bagaimana mengelola hutan dengan baik sehingga tidak ada dampak bencana longsor pada lingkungan masyarakat. Kegiatan ini juga dapat menambah kesiapan masyarakat tentang pengetahuan mitigasi bencana

\section{DAFTAR PUSTAKA}

Badan Geologi (PVMBG), (2013). Prakiraan Potensi Terjadi Gerakan Tanah/ Tanah Longsor dan Banjir Bandang di seluruh Indoneia. PVMBG. Bandung

Bastian Affeltranger, dkk, (2007). Hidup Akrab dengan Bencana: Sebuah Tinjauan Global tentang Inisiatif-inisiatif Pengurangan Bencana. MPBI. Jakarta

Deny Hidayati, dkk,(2006). Kajian Kesiapsiagaan Masyarakat dalam Mengantisipasi Bencana Gempa dan Tsunami di Indonesia. LIPI/UNESCO/ISDR. Jakarta

John Twigg, (2009). Karakterisrik Masyarakat Tahan Bencana: sebuah catatan panduan. Oxpam. Jonatan Lassa, dkk, (2009). Kiat Tepat Mengurangi Risiko Bencana. Pengelolaan Risiko Bencana Berbasis Masyarakat. PT. Grasindo. Jakarta

Kemen PU. Direktorat Jenderal Cipta Karya, (2010). Proyek Rehabilitasi dan Rekonstruksi Masyarakat dan Pemukiman Berbasis Komunitas: Pedoman Pendampingan Penanganan Kawasan Rawan Bencana Longsor. Rekompak JRF. Jakarta.

Laporan Profil Desa Tugumukti Kecamatan Cisarua, (2013). Badan Pemberdayaan Masyarakat dan Pemerintahan Desa Pemerintah Kabupaten Bandung Barat.

Nurul Zuriah, (2009).Penelitian tindakan dalam bidang pendidikan dan sosial. Bayumedia Publishing. Malang

Pusat Penyuluhan Sosial, (2007). Undang-undang Republik Indonesia No. 24 Tahun 2007 tentang Penanggulangan Bencana. Depsos RI. Jakarta 